\title{
A tradução de teatro segundo Luiz Francisco Rebello
}

\section{Christine Zurbach}

\section{Dente por dente, de Luiz Francisco Rebello, versão livre a partir de \\ Measure for Measure, de Shakespeare, \\ enc. António Pedro, \\ Teatro Moderno de Lisboa, 1964 (elenco completo), \\ fot. cortesia do Museu \\ Nacional de Teatro. \\ ${ }^{1}$ A entrada sobre Luiz Francisco Rebello da CETbase refere 42 textos traduzidos/adaptados (cf. <http://ww3.fl.ul.pt/CET Report.htm?0bjType=Pe ssoactobjld $=484>$ ). Ver também Santos}

Christine Zurbach é Professora Associad

com Agregação do

Departamento das

Artes da Universidade de Évora, onde leccion nas áreas dos Estudos Teatrais e Estudos de Tradução e investigadora do $\mathrm{CHAIA}$ (Centro de História de Arte e Investigaçã Artística). É ainda

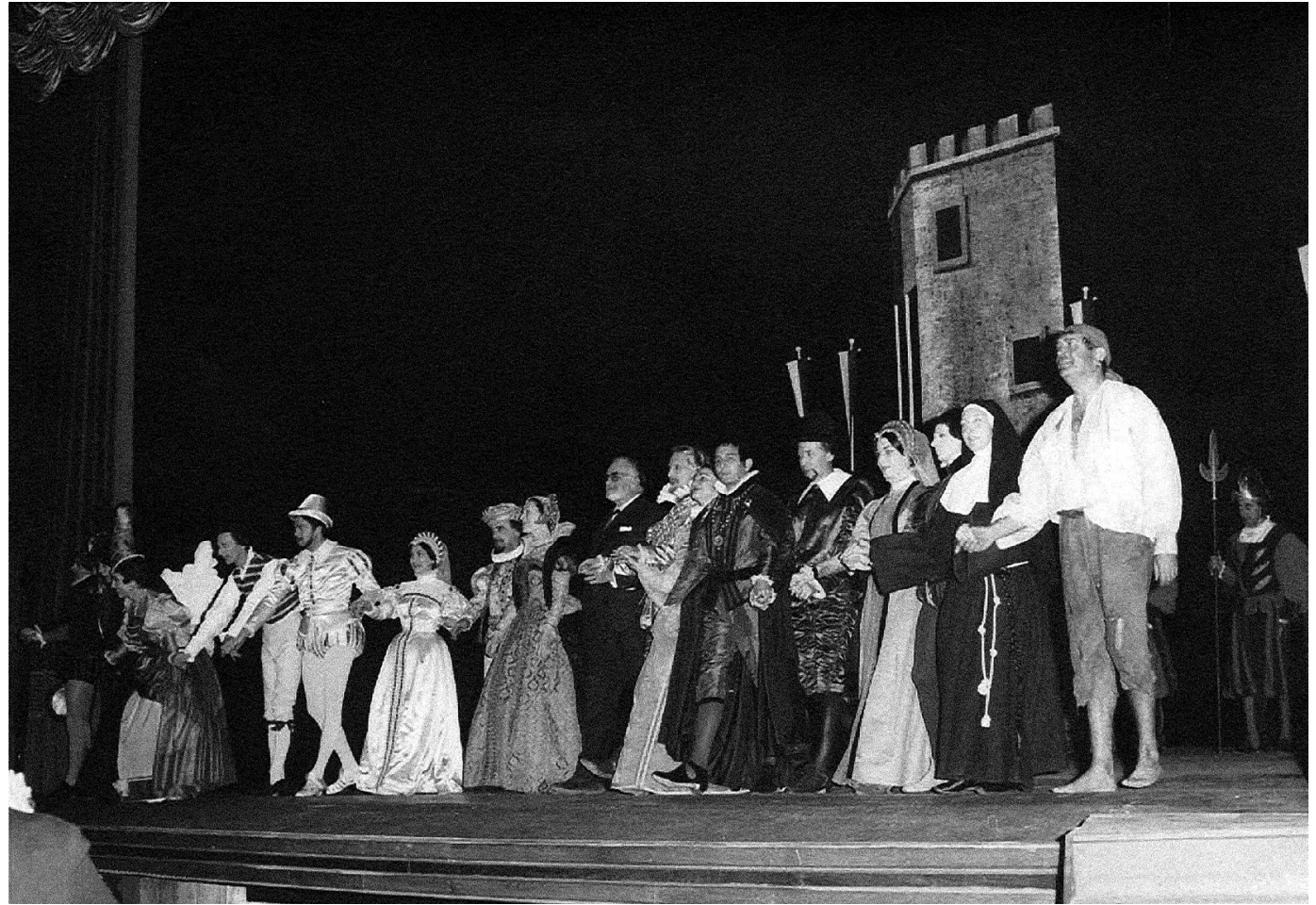

Menos conhecida do que o seu trabalho de historiador dramaturgo e ensaísta, a tradução de teatro tem um lugar destacado na obra do dramaturgo Luiz Francisco Rebello (1924-2011). Foi uma actividade que iniciou nos anos 1940, que praticou regularmente e que resultou numa abundante produção de peças traduzidas. No espólio que nos deixou encontramos cerca de quatro dezenas de traduções e adaptações. Representam um grande número de autores, sobretudo contemporâneos, em cena nessa altura nos grandes palcos europeus. Com efeito, Luiz Francisco Rebello foi um tradutor ciente de que, em qualquer cultura, a tradução é o veículo privilegiado para a importação de textos e de autores e também de modelos estéticoteatrais disponibilizados deste modo para um público actual. Ao longo da História, em determinados contextos sociopolíticos, ela representou frequentemente um factor poderoso de inovação e, por essa via, também de renovação dos repertórios literários e teatrais. No caso português, como é sabido, tal sucedeu em diversos contextos do passado, mais ou menos favoráveis à abertura para os contactos entre as literaturas e as culturas. No período específico em que viveu Luiz Francisco Rebello, marcado por uma mudança de regime em 1974, a tradução teve de conviver com a censura até ao 25 de Abril, o que se revelou um factor de peso na sua prática intelectual.

Se a consulta da lista que consta nos apontamentos biobibliográficos disponiveis, em particular na CETbase da Faculdade de Letras da Universidade de Lisboa", pode surpreender pela diversidade das línguas, dos géneros e das épocas que compõem o repertório do tradutor Luiz Francisco Rebello, também confirma a sua vasta cultura e o seu eclectismo: encontramos Eduardo De Filippo, Armand Salacrou, Gorki, Marguerite Duras, Félicien Marceau, António Buero Vallejo, Flávio Rangel, Millor Fernandes, F. García Lorca, Ibsen, Brecht, Tchekov, Beckett, etc. Neste último caso, o de Samuel Beckett, o número dos títulos traduzidos é revelador de uma atenção particular do dramaturgo a um nome maior da dramaturgia mundial, 


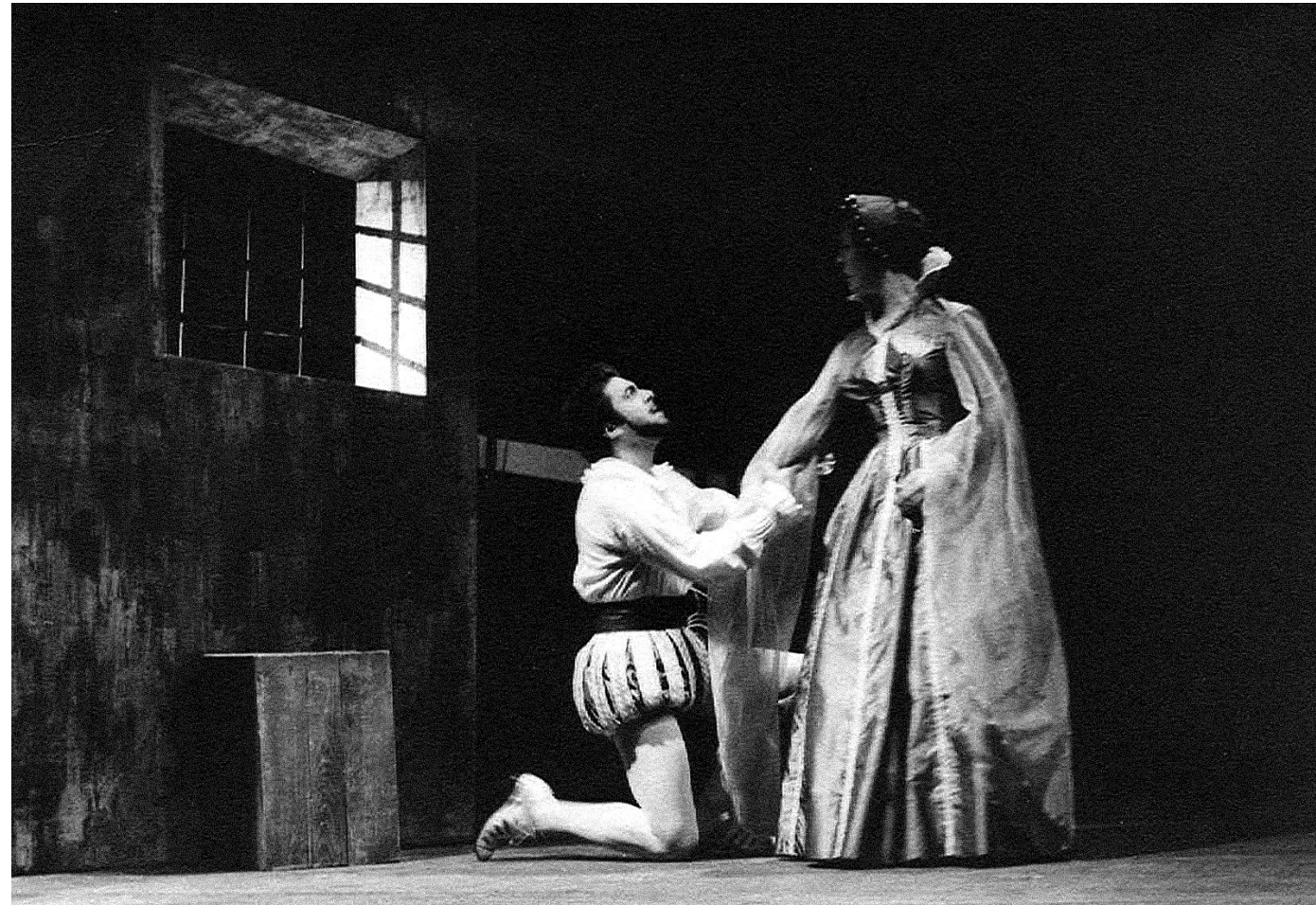

que também importava difundir em Portugal ${ }^{2}$

No caso de Luiz Francisco Rebello, o que caracteriza igualmente o seu trabalho de tradutor é ter sido frequentemente produzido em parceria com outras figuras importantes da vida intelectual e teatral do país como Orlando Vitorino, Gino Saviotti, Jaime Salazar Sampaio, Costa Ferreira, Eduardo Jacques, Luís de Lima, Helder Costa e, com regularidade nos anos 1970 e 1980, com o encenador João Lourenço e a sua colaboradora, a dramaturgista Vera San Payo de Lemos. Verifica-se, de facto, que as traduções, de que temos conhecimento, foram produzidas na sua grande maioria para agentes envolvidos na prática artística e institucional do teatro, e em espaços consagrados, como o Teatro da Trindade, o Teatro Vasco Santana, o Teatro Villaret, o Teatro de Campolide, o Teatro Aberto, entre os mais frequentes.

A colaboração com a companhia do Teatro Aberto merece um destaque particular, pelo número de traduções associadas ao repertório da companhia e pelo modelo de trabalho desenvolvido, que segue uma tipologia próxima do modelo brechtiano no qual o tradutor integra uma equipa de dramaturgia e encenação para a montagem de um texto. Em 1976, a colaboração tem início com 0 círculo de giz caucasiano, de Bertolt Brecht, traduzido com João Lourenço ${ }^{3}$. Em 1982 surge Oiçam como eu respiro, de Dario Fo e Franca Rame, em parceria com João Lourenço, Vera San Payo de Lemos e José Fanha; em 1983, 0 suicidário de Nikolai Erdmann, com os mesmos colaboradores; em 1984, de novo, Brecht e A boa pessoa de Se-Tsuang, e a mesma partilha no trabalho de tradução; no mesmo ano, Encontros numa esplanada de Verão, inclui peças traduzidas por Luiz Francisco Rebello: de Tchekov ${ }^{4}, 0$ trágico à força de Strindberg ${ }^{5}$, A mais forte, de Pirandello, 0 homem da flor na boca, e de Samuel Beckett, A última gravação. Em 1987, a tradução de uma obra de Georges Feydeau, A dama do Maxim's, voltará a juntar Luiz Francisco Rebello, Vera San Payo de Lemos e João Lourenço. um conjunto de quatro peças em um acto intitulado
Dente por dent

de Luiz Francisco Rebello, versão livre a partir de Measure for Measure de Shakespeare enc. António Pedro, Teatro Moderno de Lisboa 1964 (Morais e Castro e Carmen Dolores), fot cortesia do Museu Nacional de Teatro.

${ }^{2}$ As peças breves de Beckett traduzidas por Luiz Francisco Rebello inseridas em produções da companhia do Teatro Experimental do Porto, do Chiado, do Novo Grupo são: A última bobina de Krapp, Acto sem palavras Acto sem palavras II, Balanceada, Catástrofe, Fôlego, 0 improviso d'Ohio (fonte CETbase).

${ }^{3}$ Do mesmo dramaturgo em 1981, Luiz Francisco Rebello traduzirá $A$ excepção e a regra, para o Teatro de Campolide.

${ }^{4}$ De Tchekov, também traduziu 0 urso e Os maleficios do tabaco

${ }^{5}$ De Strindberg, também traduziu Credores, para o Teatro de Animação de Setúbal em 1980, e, muito antes, 0 pária, para 0 Teatro Moderno em 1963 
de Luiz Francisco Rebello,

versão livre a partir de

Measure for Measure

de Shakespeare,

enc. António Pedro,

Teatro Moderno de Lisboa,

1964

(Jaime Santos,

Fernando Gusmão

e Carmen Dolores),

fot. cortesia do Museu

Nacional de Teatro.

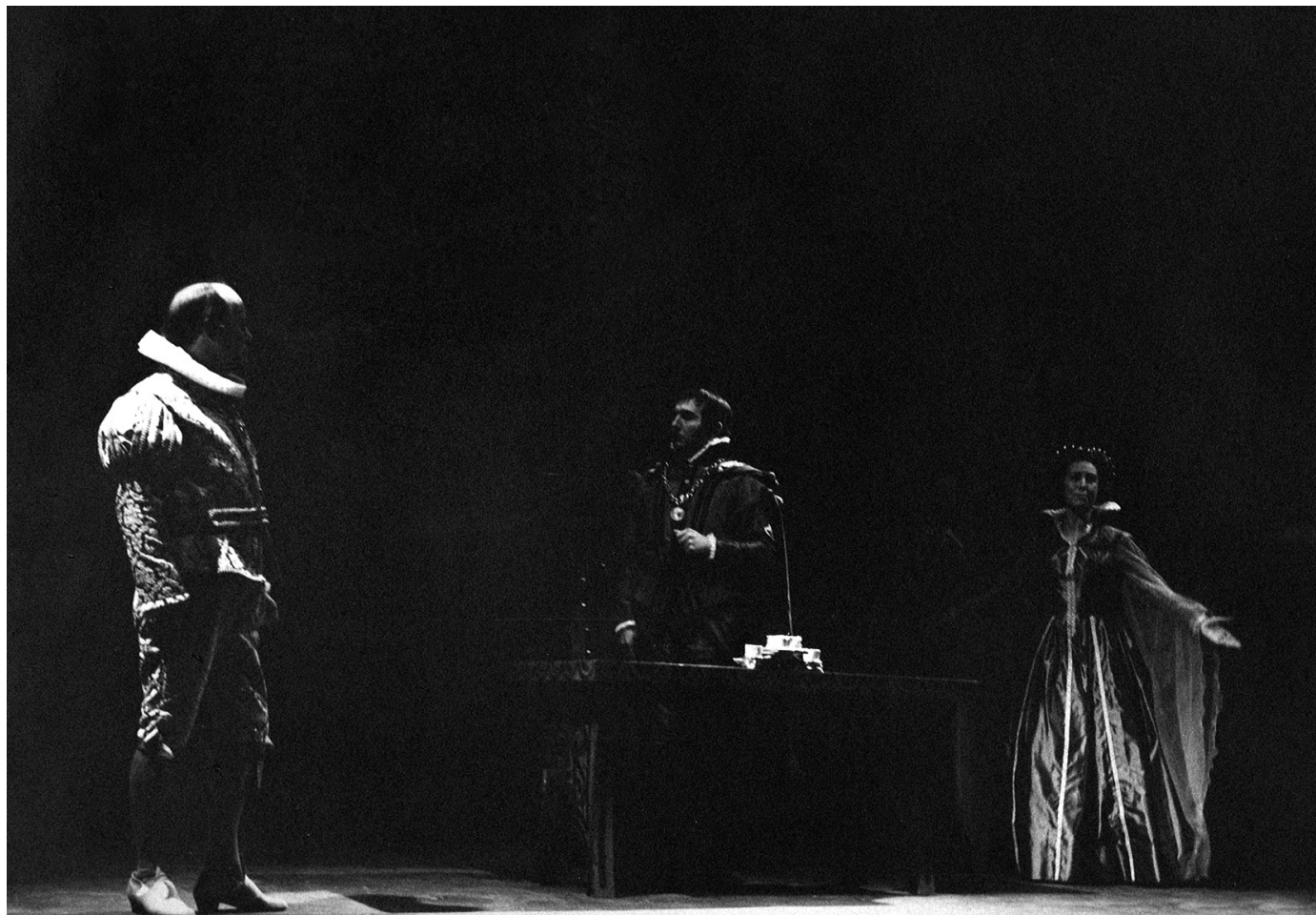

O envolvimento do dramaturgo em projectos com profissionais de teatro é antigo e passou por momentoschave da sua carreira no teatro em que se empenhou na fundação de companhias de repertório. Criou, em 1946, o Teatro-Estúdio do Salitre, com Gino Saviotti e Vasco Mendonça Alves, cuja estética de tipo experimental se afastava do naturalismo reinante como consta no "Manifesto do Essencialismo Teatral", uma carta de intenções estéticas e artísticas do grupo ${ }^{6}$. Após esta primeira experiência seguiu-se, em 1948, a co-fundação com Jorge de Faria, Adolfo Casais Monteiro, Jorge de Sena, José Blanc de Portugal, António Pedro, Costa Ferreira e José-Augusto França, de Os Companheiros do Pátio das Comédias, uma companhia profissional ${ }^{7}$. Em 1971 estará de novo à frente da direcção de uma instituição, a do Teatro Municipal São Luiz, cargo a que foi chamado por convite, mas de que se demite, em protesto contra a censura que inviabilizou 0 espectáculo A mãe de Witkiewitz.

No termo deste breve percurso introdutório, tornouse evidente que, enquanto instrumento verdadeiramente dramatúrgico e teatral, a tradução encontrou em Luiz Francisco Rebello o cúmplice privilegiado da sua passagem para o palco ${ }^{8}$. É preciso acrescentar que tal orientação não significou uma menor atenção por parte do dramaturgo relativamente à publicação de teatro, bem patente, aliás, na criação de uma colecção de textos de teatro para a editora Prelo, com um título bem representativo do gosto do dramaturgo pela contemporaneidade: "Repertório para um teatro actual", na qual figura um caso que passamos a descrever: a de adaptação, numa versão livre, da obra de um clássico intemporal, o dramaturgo Shakespeare.

No seu prefácio ao segundo tomo das obras completas de Rebello, o crítico António Braz Teixeira apresenta o autor como um dramaturgo "próximo de algum Brecht, [que] não hesita em enveredar pela directa e datada apologia político-social" (Teixeira apud Rebello 2006: 13). $\mathrm{Na}$ verdade, o retrato por Braz Teixeira de um dramaturgo brechtiano refere-se a um texto em particular: "Posição singular, a mais de um título, na obra de Luiz Francisco Rebello [ocupa] a sua versão livre da tragicomédia shakespeariana Measure for Measure, intitulada Dente por dente (1964)" (ibid.). Considera-a, com efeito, "uma verdadeira recriação da obra do genial inglês, que, respeitando embora o espírito do texto original, o afeiçoa ao modo, ao estilo e à visão do dramaturgo português [...]" . Brechtiana ou não, esta versão reconhece e reivindica a sua dívida em relação a uma dramaturgia que, em grande medida, foi também construida com recurso a uma prática de reescrita ou de adaptação.

Apesar das (ou até "contra as") traduções disponiveis nas livrarias, o texto é uma encomenda. 0 Teatro Moderno de Lisboa precisava do texto de Measure for Measure em língua portuguesa para ser encenado por António Pedro, autor igualmente do cenário e dos figurinos. 0 contexto é o quarto centenário do nascimento de Shakespeare, ocasião para dar a conhecer a peça a um público de espectadores, e não de leitores eruditos. 0 que não impede que o texto seja publicado no mesmo ano, em 1964, dez dias depois da estreia, pela editora Prelo, de Lisboa, constituindo o segundo volume da colecção "Repertório para um teatro actual" dirigida pelo próprio Luiz Francisco Rebello.

Intitulada Dente por dente (Measure for Measure) de William Shakespeare, a peça é apresentada como uma "tragicomédia em duas partes, livremente adaptada por Luiz Francisco Rebello" (Rebello 1964: 3). Shakespeare é, nos anos 1960, o que se chama um clássico. E, naquele tempo, "Oue fazer dos clássicos?" era uma questão de actualidade nos repertórios europeus. Não há dúvida de que Luiz Francisco Rebello e outros artistas de teatro em Portugal estão ao corrente do debate estético e ideológico (um debate sobretudo de encenadores) em torno da problemática que levanta a questão do "bom" uso das obras antigas para um novo público, o do pós-guerra, tão no espírito, nomeadamente, do "théâtre populaire" francês. 


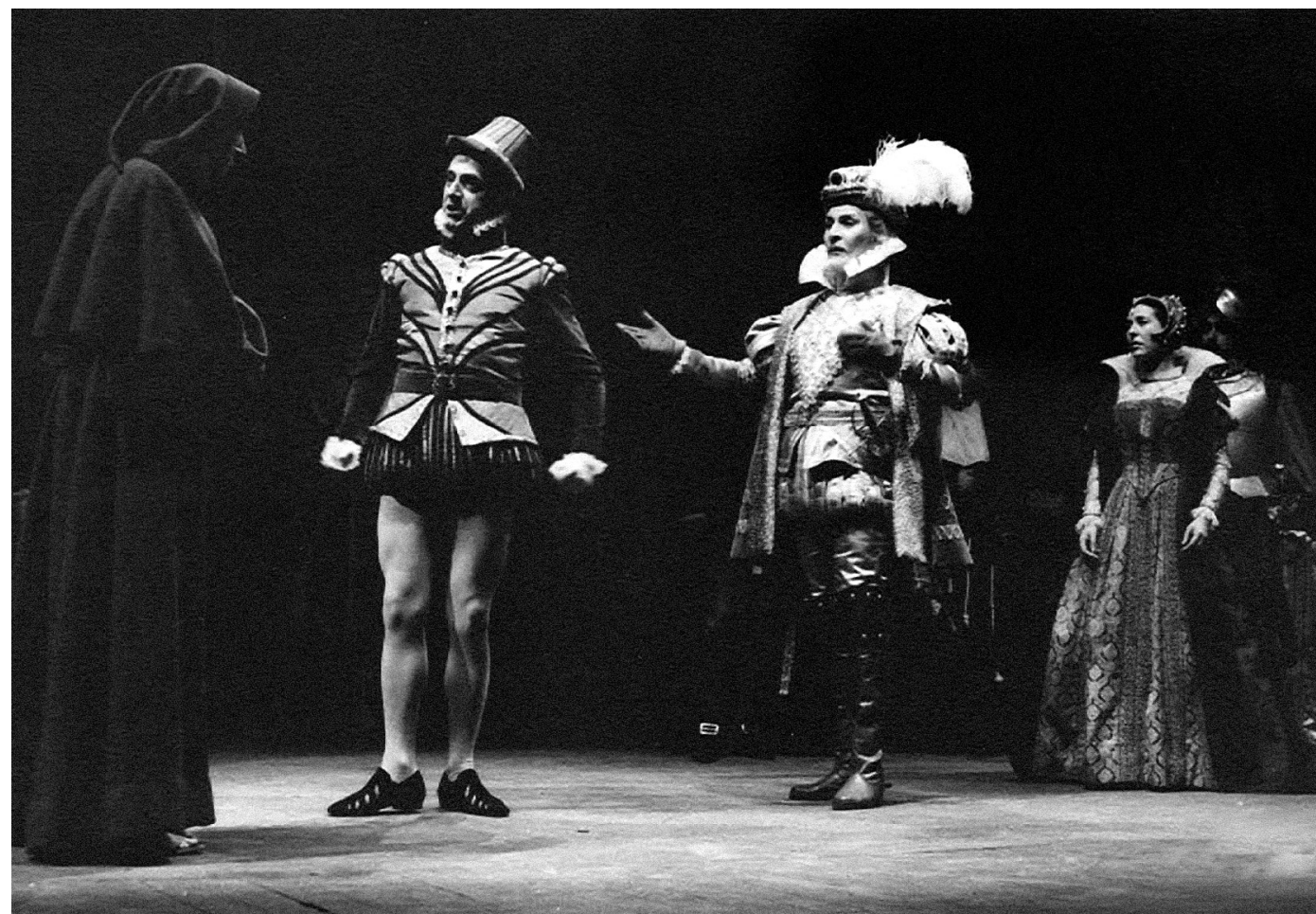

A nota de apresentação, assinada pelo tradutor / adaptador, começa por sublinhar a qualidade da peça, raramente representada, à excepção - como nos informa Rebello, no seu papel de historiador do teatro muito atento ao teatro do seu tempo - de encenações em França (LugnéPoe, em 1898, Pitoëff em 1920), em Inglaterra (Tyrone Gruthrie, no Old Vic em 1933), em Itália (Luigi Squarzina, em 1957) e na Tunísia (Aly Ben Ayed, que a apresentou na temporada de 1964 no Teatro das Nações). A tradução mais recente, de Mário Braga, também é evocada, mas é considerada má e nociva para a obra. Adaptar seria assim uma espécie de fidelidade?

Se se trata de produzir um texto adaptado ao receptor, que "democratiza" a recepção teatral do texto de um autor cuja obra original pertence ao repertório elevado, mas que tem de se tornar acessivel a um vasto público, a tradução sistemática do teatro completo de Shakespeare pelo editor Lello \& Irmãos, ou pela Presença na mesma época, à venda nas livrarias, está no pólo oposto da do Teatro Moderno, que propõe uma leitura não-literária de um autor privilegiado na programação de uma cena "moderna". Mas aqui, a adaptação é também um trabalho de escrita ao serviço das lutas do teatro português dessa altura, prisioneiro dos constrangimentos de uma vida cultural e teatral severamente vigiada e censurada no plano ideológico e estético (e, enquanto dramaturgo, Rebello é uma das vítimas desse sistema repressivo). A reescrita de Measure for Measure é, mais do que um exercício de estilo, um exemplo de estratégias dramatúrgicas inscritas num teatro de oposição política ao regime nos anos 1960. À proibição da importação de um autor como Brecht e da sua obra, a peça de Rebello responde inspirando-se em e servindo-se do modelo brechtiano do teatro épico para reescrever Shakespeare.

Em vez de procurar uma definição do significado do termo "adaptação", porventura incapaz de designar aquilo que a distinguiria claramente duma (verdadeira) tradução, diria que o recurso ao termo é uma solução cómoda para designar um texto que, inegavelmente construído a partir de outro texto pertencente a uma literatura e a uma língua estrangeiras, não corresponde a uma tradução, ou pelo menos àquilo que nos habituámos a entender por esse termo. No teatro, a adaptação é um procedimento de escrita que envolve a dramaturgia, o que pode permitir, ou até ter intencionalmente em vista, a importação de um modelo dramatúrgico novo, com o objectivo de promover um trabalho sobre a interpretação e o sentido da obra, indo, portanto, mais além do que a transposição linguistica ou literária.

Neste caso, Luiz Francisco Rebello recorre a um ponto de partida dramatúrgico brechtiano, bem visivel nas modificações do texto que são duplamente legitimadas pelo próprio em prefácios ou posfácios explicativos e que remetem o leitor para Shakespeare e Brecht, mestres na matéria. Exprimindo-se sobre a reescrita feita por Shakespeare, o primeiro adaptador, que classifica como uma "verdadeira criação, no legítimo sentido do termo", o tradutor/adaptador afirma um direito à mesma liberdade face ao texto, idêntica à de Molière ou de Brecht, segundo ele. Shakespeare transformava a narrativa em prosa numa peça para ser representada: a situação é igual para Rebello que acrescenta que "uma tradução literal dificilmente se acomodaria às exigências práticas irrecusáveis de uma realização cénica actual do texto de Shakespeare" (Rebello 1964: 9). Além disso, ao interrogar-se sobre as razões de uma tal independência do artista em relação às suas fontes de inspiração, sobre "os fundamentos do direito de transformar em obra própria a obra alheia" (ibid.), Rebello defende que o público é o grande argumento, aquele que ele chama a outra metade dum autor dramático.

Donde a sua escolha: antes uma fidelidade irreverente em relação ao texto original do que um respeito infiel, antes sacrificar a letra para manter o espírito (uma teoria da tradução teatral está subjacente a este discurso). Alguns 


\section{repertorio pana um teatro actual}

dente por dente - william shakespeare

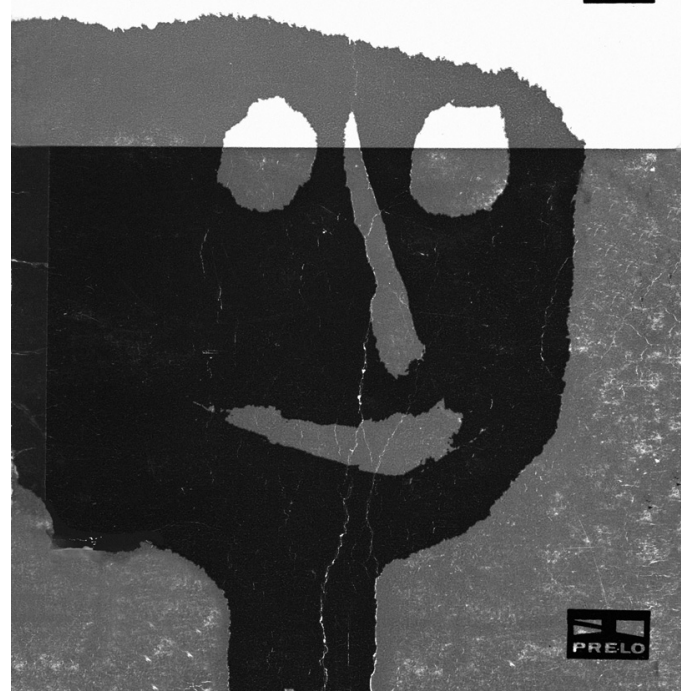

do seu Todo o teatro, mas a sua história ainda não foi feita. Nela, a tradução terá de ter o seu lugar, e estou certa de que Luiz Francisco Rebello seria o primeiro a reconhecê-lo ou mesmo a reivindicá-lo, ele que não hesitou em incluir a sua adaptação Dente por denteno volume II que reúne a sua obra original. Esta escolha não desmente o lugar que ocupa junto dos estudiosos do teatro em Portugal, a de um historiador engajado, no que o distingue da investigação académica, mais tímida e mais neutra (a que preço, tantas vezes...), e confere um valor inestimável ao legado que nos deixou.

\section{Referências bibliográficas}

FADDA, Sebastiana (2012), "O fulgor duma inteligência apaixonada: Imagens da dramaturgia de Luiz Francisco Rebello", in Sinais de cena, n. 17, Junho, pp. 19-32.

REBELLO, Luiz Francisco (1964), Dente por dente (Measure for Measure) de William Shakespeare, Lisboa, Prelo.

-- (2006), Todo o teatro, Lisboa, Imprensa Nacional-Casa da Moeda.

SANTOS, Luisa Duarte (org.) (2010), Os autos da vida de Luiz Francisco Rebello. Catálogo da exposição, Vila Franca de Xira, Câmara Municipal de Vila Franca de Xira - Museu do Neo-Realismo

SERÔDIO, Maria Helena (2012), "Luiz Francisco Rebello: 0 escândalo da clareza", in Sinais de cena, n. ${ }^{17}$, Junho, pp. 51-55.

\section{Sitiografia}

http://ww3.fl.ul.pt/CETbase| 